\title{
A reelaboração do transcendental em Merleau-Ponty
}

\author{
Marcus Sacrini \\ sacrini@usp.br \\ Universidade de São Paulo, São Paulo, Brasil
}

resumo Neste artigo, defendo que Merleau-Ponty reformula a filosofia transcendental de matiz kantiano no sentido de mostrar que as condições a priori da experiência não podem ser separadas das vivências concretas do sujeito encarnado. Na primeira seção, eu retorno a Kant e Husserl para analisar como esses autores delimitam as condições transcendentais como um domínio formal independente de qualquer experiência concreta. Em seguida, eu reconstruo o movimento argumentativo pelo qual Merleau-Ponty rejeita essa delimitação formal da esfera transcendental e reapresenta essa última como inseparável do domínio empírico, inicialmente em $A$ estrutura do comportamento (seção 2) e posteriormente em Fenomenologia da percepção (seção 3).

palavras-chave Merleau-Ponty; transcendental; Gestalt; circularidade existencial

\section{Introdução}

Há um debate já bastante desenvolvido acerca da filiação de MerleauPonty à filosofia transcendental. Há comentadores que rejeitam que tal filiação tenha ocorrido, mas isso simplesmente por causa da incapacidade de Merleau-Ponty apresentar uma reflexão transcendental completa, uma vez que ele teria acentuado excessivamente a experiência concreta dos sujeitos encarnados ${ }^{1}$. Outros defendem que Merleau-Ponty voluntariamente não quis se filiar à tradição transcendental, já que suas descrições da intencionalidade perceptivo-motora estão muito mais próximas de algumas investigações científicas contemporâneas (psicologia, ciências 


\section{8}

cognitivas, etc. $)^{2}$. Um terceiro grupo de autores considera que ao menos em certas passagens sobre a intencionalidade perceptivo-motora Merleau-Ponty propõe explicitamente argumentos transcendentais, os quais são construídos da mesma maneira que aqueles de Kant e Husserl ${ }^{3}$. Por fim, alguns autores, entre os quais eu me encontro, consideram que Merleau-Ponty desenvolve voluntariamente uma abordagem transcendental ligada às suas análises da intencionalidade perceptivo-motora, mas uma abordagem que é substancialmente modificada em relação àquela de Kant e Husserl ${ }^{4}$. Os defensores dessa última posição têm a dificuldade adicional de elucidar quais são as principais características dessa nova abordagem transcendental. É exatamente o problema geral que enfrentarei neste texto. Pretendo assim não só clarificar por que é correto atribuir um projeto transcendental a Merleau-Ponty, mas também reconstruir as suas teses principais.

Qualquer tentativa de qualificar um projeto filosófico como "transcendental" deve primeiramente delimitar os aspectos básicos daquilo que se entende sob esse termo. O próprio Merleau-Ponty oferece críticas diretas ao que ele circunscreve como filosofias transcendentais clássicas na Fenomenologia da Percepção (MERLEAU-PONTY 1997, p.73). Mas antes de expor tais críticas, e no intuito de torná-las mais compreensíveis, eu gostaria de apresentar algumas das teses dos principais autores que compõem o quadro clássico da filosofia transcendental para MerleauPonty, a saber, Kant e Husserl.

Inicialmente trata-se de recuperar os aspectos por meio dos quais a própria ideia de filosofia transcendental foi constituída na obra de Kant. Para tanto, eu me sirvo de uma caracterização tripartite do transcendental kantiano proposta por Derk Pereboom (1990). Tal como sugerido de maneira bastante convincente por esse autor, três noções compõem o sentido da esfera transcendental para Kant:

a) Kant associa o transcendental aos modos subjetivos pelos quais se pode estabelecer conhecimento a priori (Cf. KANT 1998, B 25). Assim, uma investigação transcendental não se interessa pelos objetos do conheci- 
mento, mas pelas estruturas subjetivas por meio das quais, de modo a priori, objetos podem ser conhecidos (e o a priori aqui denota o que é independente e precede as experiências particulares).

b) Kant associa esses modos subjetivos a priori a condições de possibilidade que todo conhecimento da experiência sensível deve satisfazer a fim de ser corretamente estabelecido (Cf. KANT 2004, p.125, nota).

c) $\mathrm{O}$ transcendental também indica um tipo de reflexão capaz de remeter todas as representações às suas origens nas faculdades cognitivas correspondentes, ou seja, capaz de explicitar as fontes subjetivas a priori de quaisquer representações conscientes (Cf. KANT 1998, A 261 / B 317).

Pereboom sugere que a noção de transcendental, enquanto síntese desses três aspectos, constitui um ponto de vista especial que permite ao filósofo explorar as faculdades cognitivas em seus aspectos puros (independentes do uso empírico), de modo a revelar as condições de todo conhecimento possível, condições que também são fonte das representações subjetivas (Cf. PEREBOOM 1990, p.28). Eu concordo com tal conclusão e gostaria de extrair dela uma consequência relativa à esfera empírica. Essa esfera pode ser definida por contraste com o domínio transcendental: o empírico se refere ao exercício das faculdades cognitivas, isto é, à sua presunção (bem sucedida ou não) de conhecer os objetos mundanos, uma presunção que não se submete somente às condições $a$ priori, mas também às circunstâncias factuais do uso do aparato cognitivo em situações concretas. A esfera empírica é assim marcada por aspectos contingentes, cuja influência nas situações cognitivas não implica nem necessidade nem universalidade. Além da contingência, o que também marca a esfera empírica, na concepção kantiana, é a incapacidade de revelar a própria origem de sua atividade. No uso empírico, as faculdades cognitivas estão voltadas para os objetos mundanos e não refletem sobre o seu próprio funcionamento como condições e fontes puras do conhecimento. Supõe-se aqui que tais condições puras tenham sido realizadas, já que muitas vezes o conhecimento empírico é efetivamente obtido, mas não é claro, nesse nível, como foi possível, no que se refere às condições subjetivas a priori, a obtenção de tal conhecimento.

Chega-se aqui a uma dicotomia notável entre o transcendental e o empírico: o primeiro designa um ponto de vista a partir do qual o sujeito cognitivo não está limitado ao funcionamento comum de suas faculdades 
(voltadas para os objetos), um ponto de vista que o capacitaria a explicitar as fontes puras de todo conhecimento, independentemente da inserção das capacidades cognitivas em situações concretas. O empírico, por sua vez, designa principalmente uma atividade que ignora sua origem e condições a priori; trata-se aqui de um envolvimento na maior parte das vezes irrefletido com as coisas e situações mundanas, um envolvimento incapaz de esclarecer as condições de sua própria objetividade, quando essa é obtida ${ }^{5}$.

Passo agora a considerar o sentido do domínio transcendental ao menos no período intermediário da filosofia de Husserl, no qual haverá um contraste com a esfera empírica ainda mais radical que aquele inferido da posição kantiana. Esse período é precisamente aquele que Merleau-Ponty associa à filosofia transcendental tradicional' .

Entre 1906 e 1907, Husserl torna pública sua primeira versão da fenomenologia transcendental em dois cursos, Introdução à lógica e à teoria do conhecimento e $A$ ideia da fenomenologia, e estabelece as bases do que será depois exposto com detalhe no livro Ideias para uma fenomenologia pura $e$ uma filosofia fenomenológica I (publicado em 1913). O procedimento metodológico mais marcante aí desenvolvido é a redução fenomenológica (Cf. HUSSERL 2008, \$ 36), um tipo de reflexão por meio da qual a validade das crenças espontâneas na existência dos objetos é suspensa. Normalmente, naquilo que Husserl chama de orientação natural do pensar, a consciência está voltada para as coisas e situações mundanas, as quais são tomadas como existindo independentemente desse voltar-se para elas. Ao se suspender essa crença na existência autônoma das coisas (pela aplicação da redução fenomenológica), restam os puros fenômenos, ou seja, os objetos enquanto correlatos da consciência. Os fenômenos, dados evidentes, servirão de base para compreender como a afirmação da existência independente do mundo é uma tese constituída sobre aquilo que é diretamente intuído pela consciência. Dessa forma, a redução fenomenológica revela o papel ativo da consciência na constituição de nossa experiência mundana.

Com efeito, não somente crenças espontâneas são suspensas pela redução fenomenológica, mas também a validade objetiva de todo conhecimento científico. Isso é feito justamente para que se possa clarificar como esse conhecimento é estabelecido com base nas estruturas 
essenciais da consciência. A fenomenologia transcendental é, assim, uma disciplina que busca elucidar a possibilidade do conhecimento e da experiência em geral, e, a fim de realizar essa tarefa, a validade de todo contato com o domínio empírico é suspensa, uma vez que se trata justamente de compreender como esse domínio pode ser conhecido.

Essa apresentação bastante sucinta da fenomenologia transcendental já me permite sugerir que Husserl preserva aqueles três aspectos que, conforme Pereboom mostrou em relação a Kant, constituem o ponto de vista transcendental. A fenomenologia propõe a suspensão do uso empírico das faculdades cognitivas para então revelar, em sua pureza a priori, as capacidades subjetivas por meio das quais o sentido de qualquer experiência é constituído. Além disso, Husserl sustenta que essas capacidades subjetivas são condições a priori para a experiência e conhecimento do mundo, já que é somente ao investigá-las que se pode entender como a subjetividade estabelece relação com o que a transcende ${ }^{7}$. Por fim, Husserl defende que ao desvelar a consciência pura como domínio de evidência apodítica, a fenomenologia pode então esclarecer qual é a origem ou fonte do conhecimento ${ }^{8}$.

Cabe aqui notar que Husserl preserva apenas em seu sentido geral esses aspectos propostos por Kant, uma vez que tece várias críticas ao modo como esse último desenvolve a noção de transcendental. Não analisarei esse tema aqui ${ }^{9}$, mas somente gostaria de observar que há uma diferença notável entre esses dois autores no que concerne ao contraste entre o empírico e o transcendental. Não é que Husserl recuse esse contraste estabelecido por Kant; pelo contrário, ele o leva ao extremo. Para Kant, o ponto de vista transcendental permitiria clarificar as condições a priori que tornam possíveis todo conhecimento e experiência humanas. Nesse caso, trata-se de investigar as condições epistêmicas aos quais o gênero humano está submetido. Por sua vez, o que Husserl almeja descrever são as essências dos atos de consciência e dos fenômenos correlatos. Descrever a consciência nesse nível eidético significa descrever as características gerais e necessárias da consciência, as quais, para Husserl, são independentes de quaisquer particularidades factuais, mesmo daquelas que se referem à totalidade do gênero humano. Em Ideias I, por exemplo, Husserl assevera que toda coisa física só pode ser apreendida pela consciência perceptiva por meio de inúmeras perspectivas parciais. Essa 


\section{2}

tese tem um valor eidético, o que significa que ela é válida "não somente para nós humanos, mas também para Deus - enquanto representante ideal do conhecimento absoluto" (HUSSERL 1950, \150, p.371). Assim, o domínio transcendental revelado pela fenomenologia não se limita aos modos a priori do conhecimento humano, mas almeja explicitar os modos do conhecimento em geral, seja ele exercido por humanos ou deuses.

A fim de realizar tal explicitação, Husserl propõe a descrição de essências ou possibilidades ideais de atos de consciência em correlação com fenômenos possíveis. Não necessariamente todas essas possibilidades que circunscrevem o domínio da consciência em geral se realizam na experiência humana. Aquelas que se atualizam nessa experiência compõem o domínio empírico. E que certas possibilidades eidéticas sejam exemplificadas na experiência humana enquanto outras jamais o serão não altera em nada o domínio transcendental, o qual é precisamente composto por essências puras. Por sua vez, as experiências empíricas não são senão a atualização contingente de algumas possibilidades ideais, as quais, para serem conhecidas em sua pureza eidética exigem uma passagem para um ponto de vista próprio, independente de quaisquer particularidades factuais. Em sua famosa conferência inaugural em Freiburg (1917), Husserl formula claramente esse ponto: "a fenomenologia pura propõe investigar o reino da consciência pura e seus fenômenos não como existem de facto mas como puras possibilidades com suas puras leis" (HUSSERL 1986, p.79). Em outras palavras, a fenomenologia transcendental não estuda fatos, mas somente essências puras, das quais os fatos são exemplos ou instâncias.

Como se vê, ao menos em certa fase do pensamento de Husserl, o transcendental é apresentado como um domínio completamente separado da experiência empírica. A partir daqui passo para a análise crítica que Merleau-Ponty propõe das filosofias transcendentais clássicas, análise que localiza talvez como aspecto mais marcante de tais filosofias essa cisão entre o transcendental e o empírico:

Esta passagem do naturado ao naturante, do constituído ao constituinte (...) nada mais deixaria de implícito ou de subentendido em meu saber.

Ela me faria tomar posse integral de minha experiência e realizaria a adequação entre o reflexionante e o refletido. Tal é a perspectiva ordinária de uma filosofia transcendental e tal é também, pelo menos 
aparentemente, o programa de uma fenomenologia transcendental (MERLEAU-PONTY 1997, p.73).

A passagem da experiência empírica a um ponto de vista dela purificado, do qual seria possível desvelar a constituição do sentido dessa experiência com base em possibilidades formais ou ideais, é o procedimento que une Kant e Husserl como protagonistas da filosofia transcendental tradicional. Merleau-Ponty detalha esse procedimento da seguinte forma:

É notável como as filosofias transcendentais do tipo clássico nunca se interrogam sobre a possibilidade de efetuar a explicitação total que elas sempre supõem feita em algum lugar. Basta-lhes que ela seja necessária, e julgam assim aquilo que é por aquilo que deve ser, por aquilo que a ideia do saber exige (Id., p.74)

As filosofias transcendentais clássicas se satisfazem com a formulação das condições necessárias e universais que tornariam possíveis quaisquer experiências concretas. O caráter necessário e universal dessas condições implicaria a sua antecedência em relação às experiências empíricas particulares, uma vez que cada uma dessas experiências deve ter satisfeito tais condições para aparecer de modo ordenado. Mas para Merleau-Ponty, esse apelo ao caráter universal e necessário de tais supostas condições é insuficiente para responder a duas críticas. A primeira já está esboçada na citação acima: deve-se questionar seriamente se é possível assumir um ponto de vista que teria acesso às essências puras ou esquemas formais responsáveis pela ordenação do sentido da experiência. A passagem a um tal ponto de vista pressupõe a purificação de todo laço com o mundo empírico, a fim de que os componentes formais ou ideias sejam desvelados em toda a sua pureza. Merleau-Ponty julga que não há como realizar tal passagem:

De fato, o Ego meditante nunca pode suprimir sua inerência a um sujeito individual que conhece todas as coisas em uma perspectiva particular. A reflexão nunca pode fazer com que eu deixe de perceber o sol a duzentos passos em um dia de neblina, de ver o sol "se levantar" e "se deitar", de pensar com os instrumentos culturais preparados por minha educação, meus esforços precedentes, minha história. Portanto, eu nunca reúno efetivamente, nunca desperto ao mesmo tempo todos 


\section{4}

os pensamentos originários que contribuem para minha percepção ou minha convicção presente (Id., p.74-5).

Não é possível para o sujeito que reflete abandonar completamente sua inerência a um corpo e às circunstâncias factuais. Os sujeitos humanos estão irremediavelmente envolvidos em eventos empíricos por meio de seus corpos, e essa inserção primordial no mundo implica que "esta possibilidade de ausência, esta dimensão de fuga e liberdade que a reflexão abre nas profundezas de nosso ser, e que é chamada de eu transcendental, em primeiro lugar não [são] dadas e nunca absolutamente adquiridas" (Id., p.241). Não é assim possível mover-se a um ponto de vista purificado de todo laço empírico, e isso porque "todo ato de reflexão, toda tomada de posição voluntária se estabelece[m] sobre o fundo e a proposição de uma vida pré-pessoal de consciência” (Id., ibid.). Quer dizer que a reflexão filosófica nunca consegue verdadeiramente constituir um domínio transcendental autônomo, com base no qual se poderia desvelar a origem a priori de todo conhecimento e experiência (origem válida não só para as experiências humanas, mas para a experiência geral, como queria Husserl). O sujeito que reflete, que busca desvelar as condições $a$ priori é um sujeito encarnado e, nesse sentido, irremediavelmente engajado em situações empíricas das quais não pode se livrar totalmente para atingir um ponto de vista privilegiado ${ }^{10}$. Obviamente pela reflexão se pode considerar inúmeras circunstancias factuais diferentes, se pode tentar buscar os invariantes formais dessas circunstâncias, mas nada disso apaga o fato de que a capacidade reflexiva dos sujeitos está sustentada por estruturas factuais (a vida pré-pessoal do corpo inserido nas situações mundanas).

A segunda crítica é que um ponto de vista obtido por uma reflexão purificadora dos laços sensíveis elude o problema da inserção da consciência na experiência sensível. Assim, mesmo se fosse possível atingir um tal ponto de vista, isso não seria de grande ajuda para tornar compreensível a inserção concreta do sujeito nas circunstâncias empíricas. As filosofias transcendentais clássicas sugerem que o acesso à esfera transcendental pura supõe a remoção de todo laço com a empiria, de modo que "nunca se tem de se perguntar como o mesmo sujeito vem a ser parte do mundo e seu princípio" (Id., p.51). Contenta-se em explicitar as supostas restrições universais e necessárias para qualquer experiência 
possível, sem jamais se atentar para as particularidades das vivências empíricas concretas, as quais, como já foi comentado, servem de base para a atividade reflexiva. É notável, em relação a esse tópico, que a estratégia das filosofias transcendentais clássicas, particularmente do kantismo (assim julga Merleau-Ponty), seja duplicar as operações empíricas do sujeito em um domínio puro, no qual então elas seriam desveladas como princípios e sínteses formais responsáveis pela ordenação de qualquer experiência e conhecimento possíveis. No entanto, "quando eu penso em algo no momento presente, a garantia de uma síntese intemporal é insuficiente e mesmo desnecessária para fundar meu pensamento" (Id., p.150). Um ato de pensamento é sempre realizado por sujeitos que se encontram envolvidos em situações concretas. De nada adianta reconhecer quais são as operações em atuação nos casos empíricos e simplesmente postulá-las como princípios puros que então sustentariam todos os casos particulares, pois antes de serem reconhecidas em sua pureza, as operações já estavam atuando concretamente. É essa atuação concreta que deveria ser investigada e, tal como Merleau-Ponty proporá de maneira bastante ousada, reconhecida como o verdadeiro domínio transcendental. A fim de tornar compreensível essa proposta, gostaria de acompanhar o seu desenvolvimento no primeiro livro publicado por Merleau-Ponty, $A$ estrutura do comportamento.

A tarefa principal de $A$ estrutura do comportamento é "entender as relações da consciência e da natureza" (MERLEAU-PONTY 2002, p.1) para além dos parâmetros fixados por duas escolas clássicas, o neokantismo e o pensamento causal linear. Grosso modo, de acordo com o pensamento causal linear, a consciência é determinada por estímulos do ambiente em que está inserida. Por sua vez, de acordo com o neokantismo, a natureza é um conjunto de fenômenos constituídos com base em categorias a priori da consciência. A fim de evitar essas soluções antagônicas, MerleauPonty extrai consequências filosóficas da Gestalttheorie, escola psicológica cuja noção central é a de Gestalt ou forma. Uma Gestalt é um fenômeno global cujas propriedades não são perfeitamente redutíveis às característi- 


\section{6}

cas dos seus componentes isolados. A música oferece um exemplo típico aqui: mesmo quando uma melodia é tocada em tonalidades diferentes (nas quais algumas das notas ou mesmo todas as notas são diferentes daquelas que a compunham originalmente), a sua forma geral ainda pode ser reconhecida. Há, nesse caso, uma estrutura que perdura mesmo quando seus componentes elementares são alterados, uma forma que não está inexoravelmente ligada a determinados elementos discretos.

Essa noção de Gestalt permite construir uma explicação do comportamento (animal e humano) que rejeita a linearidade causal entre estímulo e resposta. Muitos experimentos realizados pelos gestaltistas mostraram que os animais não reagem a estímulos isolados mas sim a uma forma global (na qual os estímulos estão ordenados) por meio da qual apreendem a situação vivida (Cf. MERLEAU-PONTY 2002, p.62, 88). É em relação a essa forma global que os estímulos recebem sentido, assim como as notas em função de uma melodia. Tal como Bimbenet observa (2004, p.53-5), essas formas ou padrões de distribuição dos estímulos percebidos exprimem as estruturas biológicas por meio das quais os organismos delimitam um ambiente significativo para sua sobrevivência. Por exemplo, dado que certos organismos possuem uma estrutura auditiva preponderante (coelhos, morcegos, etc.), certas Gestalten auditivas estáveis são privilegiadas em seu comportamento. Há assim uma delimitação do ambiente significativo (em formas perceptivas) conforme as estruturas orgânicas que é anterior à determinação causal linear do comportamento por estímulos objetivos. É porque o organismo existe por meio de certas estruturas corporais (as quais definem as estruturas de um campo fenomenal) que certos estímulos podem ser apreendidos como significativos. Assim, é verdade que os organismos reagem aos estímulos ambientais; porém, tais estímulos, a fim de motivar tais reações comportamentais, devem ser compatíveis com as estruturas por meio das quais os organismos estão inseridos no mundo. Cada reação atual supõe uma delimitação geral do âmbito das situações significativas para o tipo de animal em questão. A relação entre estimulação e delimitação geral de um campo significativo é, desse modo, não linear, mas circular (Cf. MERLEAU-PONTY 2002, p.140): por um lado, a estimulação ativa as estruturas orgânicas, mas, por outro, são as estruturas, ao delimitarem o âmbito daquilo que é significativo para o organismo, que tornam a eficácia de tal estimulação possível. 
Merleau-Ponty crê que o pensamento causal linear e o neokantismo ignoram essa circularidade e, por causa disso, oferecem explicações insuficientes do comportamento animal e humano. Aqui é importante acentuar a crítica ao neokantismo, já que será por contraste com essa escola que Merleau-Ponty assumirá uma nova postura transcendental.

O quadro teórico geral usado pelo neokantismo para entender a relação do sujeito com a natureza se baseia na constituição da experiência por meio das sínteses cognitivas da consciência. Entretanto, essa constituição não captura a especificidade do comportamento animal/ humano. Para Merleau-Ponty,

“Também não serviria de nada dizer que o comportamento "é

consciente' e que ele nos revela como seu reverso um ser para si escondido atrás do corpo visível. Os gestos do comportamento (...) não deixam transparecer uma consciência, ou seja, um ser do qual toda a essência é conhecer, mas uma certa maneira de tratar o mundo, de 'ser no mundo' ou de 'existir"” (MERLEAU-PONTY 2002, p.136).

O comportamento não é uma expressão de poderes cognitivos a priori; trata-se da instituição de um tipo de relação "existencial” com o mundo, esse parece o sentido da posição defendida por Merleau-Ponty. Gostaria de explorar com algum detalhe essa tese.

Para Merleau-Ponty, como tentei mostrar, o comportamento estabelece um domínio de formas perceptivas privilegiadas (em conformidade com as estruturas orgânicas) por meio das quais os eventos mundanos são apreendidos. A exploração filosófica do que está implicado na formação desse domínio sugere um novo entendimento das relações entre natureza e consciência. Por um lado, a natureza não pode ser reduzida a fenômenos constituídos segundo regras a priori, uma vez que ela se apresenta em estímulos concretos que afetam diretamente os organismos, sendo apreendidos por esses numa relação não primordialmente cognitiva. Por outro lado, os estímulos não são puras causas cegas, mas sempre se apresentam unidos em formas significativas as quais estão enraizadas, por fim, nas potencialidades estruturais dos organismos. Nesse sentido, a natureza não é um conjunto de eventos indiferente aos organismos, mas ela se apresenta, diretamente aos organismos, por meio das Gestalten privilegiadas ${ }^{11}$. Aparece aqui uma conexão originária entre os organismos (o 


\section{8}

que inclui a consciência humana) e a natureza, uma doação direta dessa última às capacidades estruturais dos primeiros, uma conexão que é ignorada pelo neokantismo e que Merleau-Ponty desenvolve no terceiro capítulo de $A$ estrutura do comportamento.

Nesse capítulo Merleau-Ponty se foca mais na consciência humana que no comportamento animal, embora a considere segundo o que já foi estabelecido quanto à abertura existencial para o mundo. Ali, o filósofo propõe que todo o universo conhecido pode ser considerado em termos de Gestalten privilegiadas em função das capacidades estruturais da consciência humana. O universo se apresentaria então em três ordens de fenômenos (física, vital e humana), ou seja, diferentes formas assim apreendidas pelos sujeitos humanos ${ }^{12}$. Aqui Merleau-Ponty adota explicitamente a "atitude transcendental", isto é, "uma filosofia que trata toda realidade concebível como um objeto da consciência" (MERLEAU-PONTY 2002, p.217). Ao tratar os eventos físicos, vitais e humanos como formas, Merleau-Ponty os considera como arranjos fenomenais em correlação com a consciência. Nesse sentido, "a ideia de uma filosofia transcendental, quer dizer, a ideia da consciência como constituindo o universo diante dela e apreendendo os próprios objetos numa experiência externa indubitável, parece-nos uma aquisição definitiva como primeira fase de reflexão" (Id., p.232). Aqui é preciso atenção para entender o que de fato se adquire com a atitude transcendental.

Se o universo se organiza em termos de Gestalten, e se essas sempre se manifestam para a consciência, então a consciência deve ser entendida "como meio universal" (Id., p.199), isto é, como domínio que estrutura a manifestação de qualquer evento. Aqui Merleau-Ponty parece se afiliar à escola transcendental neokantiana, a qual apresenta o mundo como o "conjunto de relações objetivas sustentadas pela consciência" (Id., p.1). Entretanto, não devemos esquecer que se trata aqui somente de uma primeira fase da reflexão, conforme a citação no parágrafo anterior. O filósofo já deixa claro no índice de seu livro que "nossa conclusão não é criticista” (Id., p.248). Assim, é verdade que Merleau-Ponty adota uma atitude transcendental, no entanto, deve-se acentuar que se trata de uma atitude que "está numa relação de mera homonímia com uma filosofia de inspiração criticista” (Id., p.223). Quer dizer que embora as posições filosóficas de Merleau-Ponty e dos neokantianos sejam chamadas de 
"transcendentais", o sentido desse termo é consideravelmente distinto em cada caso.

Cabe agora considerar qual é a fase complementar da reflexão de Merleau-Ponty, aquela pela qual ele efetivamente se distanciará do neokantismo. A tese principal que a meu ver deve ser acentuada agora é a seguinte: "a consciência para a qual a Gestalt existe não era a consciência intelectual mas a experiência perceptiva” (Id., p.227). É, assim, a atividade ou consciência perceptiva que exerce o papel de meio universal na concepção de Merleau-Ponty, e não a consciência intelectual. E há uma distinção fundamental entre esses dois tipos de consciência: o sentido dos fenômenos apreendidos perceptivelmente é aderente ao material empírico pelo qual esses fenômenos se apresentam; já o sentido advindo dos fenômenos apreendidos pela consciência intelectual (se é que ela existe tal como proposta pelos neokantianos) é derivado de uma estrutura formal a priori que ali se atualiza ${ }^{13}$. Assim, as Gestalten percebidas não são somente unidades fenomenais constituídas segundo regras subjetivas a priori, mas unidades fenomenais que desvelam um sentido intrínseco aos eventos em questão (o qual seria diretamente explicitado em Gestalten). Desse modo, a noção de Gestalt unifica sentido e existência empírica: por meio dos arranjos fenomenais nos quais os eventos são apreendidos, algum sentido se manifesta, sentido que não deve ser reduzido a uma construção subjetiva, mas que é intrínseco ao fenômeno percebido ${ }^{14}$.

Segundo Merleau-Ponty, o neokantismo rejeita esse sentido intrínseco aos fenômenos manifestado perceptivamente. Para essa escola, a consciência perceptiva é somente um caso da consciência intelectual, a qual, de modo geral, não tem contato direto com a realidade concreta e seu sentido intrínseco. A consciência perceptiva é, nesse caso, diluída em processos cognitivos, já que "toda forma de consciência pressupõe sua forma completa: a dialética do sujeito epistemológico e do objeto científico" (MERLEAU-PONTY 2002, p.217). É, assim, a consciência intelectual que exerce o papel de meio universal no neokantismo, uma consciência que se relaciona somente com representações subjetivas submetidas a regras a priori, sem jamais estar em contato direto com os eventos mundanos ${ }^{15}$.

Por sua vez, a especificidade da consciência perceptiva consiste, para Merleau-Ponty, em seu contato direto com as Gestalten fisicas, vitais e humanas, as quais se apresentam originariamente como eventos perce- 


\section{0}

bidos aos sujeitos humanos e não como objetos científicos. Há assim uma inserção espontânea da consciência perceptiva em um domínio de eventos intrinsecamente significativos, em um mundo sensível organizado em Gestalten. O sentido desses eventos está autonomamente incluído nos arranjos empíricos apresentados à percepção e não é neles projetado a partir de formas a priori.

É importante agora tentar extrair com maior clareza as diretrizes dessa nova filosofia transcendental que vai surgindo do reconhecimento de um entrelaçamento originário entre sentido e existência. Tentei mostrar que ao tomar os eventos do universo como Gestalten, MerleauPonty os considera como eventos para uma consciência que, por meio de suas estruturas, delimita as possibilidades de manifestação desses eventos. A consciência é assim reconhecida como meio universal, responsável pelo sentido dos eventos, um movimento argumentativo pelo qual Merleau-Ponty assumiu a atitude transcendental. Entretanto, essa atitude não é adotada em referência a um poder cognitivo a priori, mas sim em relação à consciência perceptiva, que está em contato direto com os arranjos materiais do mundo ${ }^{16}$. Aqui ocorre uma transformação notável da filosofia transcendental. Na seção passada, eu notei que as filosofias transcendentais clássicas buscam atingir um ponto de vista purificado de toda particularidade empírica, um ponto de vista a partir do qual se poderia desvelar todas as condições de sentido de qualquer experiência concreta. Por sua vez, Merleau-Ponty argumenta que a busca por tais condições não exige nenhuma transição para um ponto de vista purificado, uma vez que elas se apresentam como atividade perceptiva diretamente ligada aos eventos empíricos. O que Merleau-Ponty entrevê aqui é a análise transcendental como descrição da inserção "existencial" da consciência no mundo, inserção pela qual os eventos mundanos se manifestam (em arranjos gestálticos) diretamente à consciência perceptiva. A busca pelas condições gerais de sentido da experiência não deve se limitar à formulação de restrições formais independentes de toda situação concreta particular. Trata-se aqui de uma reforma profunda na investigação transcendental, a qual Merleau-Ponty sugere explicitamente da seguinte forma: "seria preciso definir a filosofia transcendental novamente de modo a integrar nela o fenômeno do real" (MERLEAUPONTY 2002, p.241). 
Volto ao exemplo da melodia para começar a elucidar essa nova filosofia transcendental almejada por Merleau-Ponty. O ponto central aqui parece ser a inseparabilidade entre o aspecto transcendental dos princípios ou regras de unidade dos fenômenos e o material empírico sobre o qual tais princípios agiriam. Uma melodia é uma forma que não pode ser reduzida à justaposição de determinadas notas, já que tal forma permanece mesmo em tonalidades compostas por diferentes notas. Nesse sentido, a melodia pode então ser concebida como uma unidade de significação que atribui funções aos dados parciais acústicos (notas) que a compõem, de modo que há um papel transcendental do fenômeno global em questão. Mas uma melodia não consiste em uma forma abstrata (que subsistiria independentemente de quaisquer notas reais) meramente exemplificada em casos empíricos. Embora a forma melódica seja uma propriedade global que excede a mera justaposição de determinadas notas empíricas, tal forma melódica sempre pressupõe que haja notas reais em uma certa relação. De maneira similar, as capacidades perceptivas humanas não são puras regras ou essências a priori, mas capacidades sempre polarizadas por situações mundanas, as quais então se revelam em seu sentido intrínseco para a consciência humana. A sugestão que Merleau-Ponty parece extrair daqui é que para estudar as capacidades perceptivas como condições transcendentais se deve então considerar tais capacidades em atuação, ou seja, enquanto exercem aquela relação existencial com o mundo.

Obviamente é possível abstrair as capacidades perceptivas de seu exercício concreto em diferentes situações e tratá-las como princípios gerais determinantes de quaisquer experiências possíveis. Esse parece mesmo ter sido o caminho adotado pelas filosofias transcendentais clássicas. Mas seria errado tomar essa teorização tardia como o verdadeiro tema da filosofia transcendental, tal como Kant e Husserl fizeram. Merleau-Ponty acredita que ao considerar as capacidades perceptivas em ação, se deve ali reconhecer que o sentido não deriva da aplicação de um poder a priori, mas da circularidade entre a consciência perceptiva (como delimitação geral de um domínio de fenômenos significativos) e os arranjos materiais (com um sentido indecomponível) enquanto mobilizam tais capacidades. Investigar somente a delimitação geral do domínio significativo (aquilo que tange somente à consciência, abstraída de suas vivências concretas) seria perder o 


\section{2}

verdadeiro transcendental, pois tal delimitação não é um poder ou regra $a$ priori que simplesmente se exemplifica em diferentes situações, mas componente de uma relação existencial circular e fundante de todo contato humano com o mundo. Daí que a investigação transcendental deva incluir o "fenômeno do real" e não mais se limitar a buscar condições puras da experiência. Mas para tanto, será preciso explorar as experiências particulares em que os parâmetros de assimilação gestáltica dos dados perceptivos são exercidos por um sujeito engajado existencialmente no mundo. É o que, a meu ver, Merleau-Ponty tenta na Fenomenologia da percepção.

Merleau-Ponty apresenta sua intenção geral na Fenomenologia da percepção da seguinte maneira: "nossa meta constante é pôr em evidência a função primordial pela qual fazemos existir para nós, pela qual assumimos o espaço, o objeto ou o instrumento, e descrever o corpo como o lugar dessa apropriação" (MERLEAU-PONTY 1997, p.180). Parece-me bastante plausível compreender esse projeto como transcendental, e isso de acordo com aquela noção formulada por Kant com base naqueles três aspectos enumerados por Pereboom. Afinal, Merleau-Ponty está propondo investigar certas capacidades subjetivas que funcionam como condição e origem de toda relação com objetos, instrumentos, etc. Contudo, aqui é preciso notar uma alteração importante do sentido de "subjetivo" em questão. $\mathrm{O}$ agente transcendental visado por Merleau-Ponty não é um conjunto de categorias formais ou uma consciência pura, mas o corpo humano concreto ou corpo próprio. E o corpo próprio tal como apresentado pela Fenomenologia da percepção é um agente pré-pessoal, cujas principais sistemas operam anonimamente ${ }^{17}$. Mesmo assim acredito que é correto entender tais operações como subjetivas, num sentido amplo, uma vez que será por meio delas que todo contato humano com qualquer transcendência possível se estabelece. Assim como as análises de Kant e Husserl, aquelas de Merleau-Ponty não estão voltadas para os objetos e suas propriedades, mas para os modos de conhecê-los, de se ter deles experiência, modos que apesar do caráter anônimo circunscrevem as condições gerais pelas quais a subjetividade se relaciona com o mundo. 
É importante notar que ao priorizar o corpo próprio como agente transcendental, ocorre uma mudança de ênfase em relação ao que fora estabelecido em $A$ estrutura do comportamento. Nesse livro, a consciência perceptiva assumia o papel de "meio universal". Mas obviamente essa consciência é uma consciência encarnada, ou seja, que existe por meio de um corpo, tema que já era mencionado no primeiro livro de MerleauPonty ${ }^{18}$. Entretanto, ali, a ênfase transcendental era posta na consciência. Por sua vez, é na Fenomenologia da percepção que Merleau-Ponty desenvolve longamente o tema da encarnação da consciência, o que o leva a privilegiar o corpo próprio como agente transcendental. Assim, afirmase, por exemplo, que "o corpo está no mundo assim como o coração no organismo; ele mantém o espetáculo visível continuamente em vida, anima-o e o alimenta interiormente, forma com ele um sistema" (MERLEAU-PONTY 1997, p.235). Aqui Merleau-Ponty claramente sugere que é o corpo, e não a consciência perceptiva considerada de per si, o responsável por sustentar o campo de experiências sensíveis por meio das quais o mundo é apresentado ao sujeito.

E também valerá para o corpo próprio algo importante que MerleauPonty estabelecera em $A$ estrutura do comportamento, a saber, que a consciência perceptiva não é só um poder a priori de delimitação de um campo de experiências significativas mas também está inserida nesse campo (uma vez que ela tem contato direto com os arranjos materiais pelos quais a própria natureza se manifesta). Na Fenomenologia da percepção, são as capacidades perceptivo-motoras do corpo as condições e origem subjetivas que circunscrevem o âmbito de experiências significativas possíveis. Mas essas capacidades estão sempre envolvidas em situações concretas delimitadas por elas mesmas. Dessa forma, aquela circularidade entre estímulo e resposta que Merleau-Ponty encontrava já no comportamento animal reaparece nas descrições do corpo próprio ${ }^{19}$. É verdade então que os estímulos só podem aparecer para nós se eles se arranjam conforme o alcance das capacidades perceptivo-motoras do corpo próprio. No entanto, essas capacidades só se exercem como tais quando estão inseridas em situações concretas ${ }^{20}$. Quer dizer, não basta assim apontar para as capacidades perceptivo-motoras como puros poderes a priori para então julgar se ter desvelado as condições transcendentais da experiência. Em seu funcionamento originário o corpo próprio não é 


\section{4}

separável das situações concretas em que está inserido. Conforme afirma Merleau-Ponty:

Só apreendemos a unidade de nosso corpo na unidade da coisa, e é a partir das coisas que nossas mãos, nossos olhos, todos os nossos órgãos dos sentidos nos aparecem como tantos instrumentos substituíveis. $\mathrm{O}$ corpo por ele mesmo, o corpo em repouso, é apenas uma massa obscura, nós o percebemos como um ser preciso e identificável quando ele se move em direção a uma coisa, enquanto ele se projeta intencionalmente para o exterior (MERLEAU-PONTY 1997, p.372).

Aqui se sugere que mesmo para conhecer quais são as capacidades corporais que dão forma aos estímulos materiais, deve-se considerar o corpo como ligado a situações factuais nas quais tais capacidades operam. Eis aqui uma consideração com enormes consequências para a investigação transcendental. As capacidades subjetivas que são tomadas como condições e origem da experiência devem ser reconhecidas, em sua manifestação original (e não em alguma teorização tardia), como envolvidas nas situações concretas por elas delimitadas. Merleau-Ponty exprime essa consequência numa passagem lapidar:

O verdadeiro transcendental (...) não é o conjunto das operações constitutivas pelas quais um mundo transparente, sem sombras e sem opacidade se exporia diante de um espectador imparcial, mas a vida ambígua em que se faz a Ursprung das transcendências, que, por uma contradição fundamental, me põe em comunicação com elas e, sobre este fundo, torna possível o conhecimento (MERLEAU-PONTY 1997, p.418-9).

Aqui o filósofo deixa claro que não são as capacidades do corpo próprio consideradas como poderes abstratos e gerais que devem ser considerados como o verdadeiro transcendental, mas a inserção dessas capacidades em situações empíricas concretas. Somente por meio de tal inserção é que tais capacidades se exercem, mesmo se posteriormente é possível se referir a elas de um modo abstrato e geral. É importante notar que essa inserção é ambígua (ou mesmo "contraditória", afirma Merleau-Ponty), no sentido de que aquilo que delimita o domínio fenomenal significativo está envolvido por esse próprio domínio. Quaisquer que sejam as difi- 
culdades que essa tese traga embutida, há ao menos uma indicação claramente positiva aqui implicada: as operações transcendentais, de delimitação e de atribuição de sentido ao domínio da experiência, não devem ser consideradas como aplicação de regras a priori ou exemplificação de essências puras, mas sim como contato originário entre o corpo próprio e seu meio . Dessa maneira, para desvelar o domínio transcendental não é necessário passar para um ponto de vista purificado de toda particularidade empírica, mas explorar a vida concreta do corpo próprio, para o qual a empiria não se apresenta só como elemento constituído por supostos poderes puros mas também como parte integrante da circularidade fundante do sentido das experiências.

A passagem para um ponto de vista purificado é na verdade denunciada por Merleau-Ponty como uma duplicação tardia do verdadeiro transcendental, o qual então é ignorado em seu papel fundante. Kant e Husserl consideravam, cada um à sua maneira, que as condições transcendentais eram restrições válidas não somente para o curso atual da experiência, mas para qualquer experiência possível. Nesse sentido, nosso mundo percebido atual é tomado como uma exemplificação de restrições formais válidas para todos os mundos possíveis. Para Merleau-Ponty, no entanto, essa concepção de que a experiência real meramente exemplifica possibilidades ideias é ilusória. Daí sua afirmação de que a reflexão transcendental clássica "não penetra até o núcleo vivo da percepção, pois ela busca as condições que a tornam possivel ou sem as quais ela não seria, em vez de desvelar a operação que a torna atual ou pela qual ela se constitui" (MERLEAU-PONTY 1997, p.48). Merleau-Ponty sugere aqui que estabelecer as condições formais de possibilidade é secundário em comparação com a análise da experiência perceptiva atual, concreta, uma vez que é com base nessa experiência que as possibilidades formais podem ser generalizadas ${ }^{22}$. Dessa maneira, seria errôneo tomar tais possibilidades como anteriores às experiências reais, já que é por meio dessas que um campo de fenômenos significativos vem a existir. E se a reflexão transcendental de fato busca as condições últimas que tornam a experiência possível, não basta apontar para generalizações ou abstrações tardias. Tal como defende Merleau-Ponty: "não somos obrigados a priori a investir o mundo das condições sem as quais ele não poderia ser pensado, pois, 
para poder ser pensado, em primeiro lugar ele deve não ser ignorado, deve existir para mim, quer dizer, ser dado" (Id., p.254). Trata-se, assim, de investigar a doação primordial do mundo ao corpo, já que aqui se desvela o verdadeiro transcendental.

Se se busca a origem última do sentido da experiência, então o tema nuclear da investigação transcendental deve ser a vida ambígua por meio da qual o corpo delimita um domínio de significatividade ao mesmo tempo em que está inserido concretamente em tal domínio. A investigação dessa vida ambígua é, portanto, a realização correta da filosofia transcendental. Em uma passagem, Merleau-Ponty sugere explicitamente que ele está completando algo apenas iniciado por Kant: "ele não seguiu até o fim o seu programa, que era o de definir nossos poderes cognitivos por nossa condição factual, [o] que devia obrigá-lo a colocar todo ser concebível sobre o fundo deste mundo aqui” (Id., p. 255). A abordagem transcendental clássica excessivamente limitou-se a considerações formais e não penetrou na verdadeira origem transcendental da experiência. Para completá-la, obviamente não basta repetir o tipo de argumento por ela fornecido, ou seja, a busca por restrições formais válidas para quaisquer mundos possíveis ${ }^{23}$. Uma filosofia transcendental ampliada almeja explicitar as vivências concretas nas quais de modo originário o sentido da experiência se constitui. Para tanto, não basta formular restrições puras, mas se deve descrever o sistema corpo próprio/mundo em atuação, tal como tenta Merleau-Ponty na Fenomenologia da percepção.

1 Gurwitsch (1957) enfatiza que Merleau-Ponty "não pergunta questões transcendentais sobre a constituição [do] mundo pré-objetivo" (p.142), o qual seria injustificadamente aceito em sua "facticidade última" (ibid.). Para Gurwitsch, uma redução fenomenológica "radical" (ibid.) procuraria pelas condições transcendentais do mundo percebido, ou seja, deveria remeter a experiência concreta do mundo ao sistema noético puro que lhe serve de condição a priori, algo que Merleau-Ponty não faz.

2 Para Dreyfus (1995), Merleau-Ponty rejeita que cada conteúdo intencional seja um conteúdo mental, e essa rejeição "está na base de sua rejeição da redução fenomenológica de Husserl" (nota 5). Esse autor não discute com mais detalhe se Merleau-Ponty buscou adotar uma posição transcendental própria. A recusa do transcendentalismo de Husserl indicaria uma recusa do transcendentalismo em geral. Em um outro texto, (DREYFUS E DREYFUS 1999, p.120), os autores acentuam a convergência entre os trabalhos de Merleau-Ponty e algumas

doispontos, Curitiba, São Carlos, vol. 9, n. 1, p.267-291, abril, 2012 
pesquisas nas ciências cognitivas, e para tanto repetem a mesma nota citada acima para indicar a distância de Merleau-Ponty em relação à tradição transcendental.

3 Stern afirma que são exemplos de argumentos transcendentais "as discussões de MerleauPonty acerca do sentido corporal em sua Fenomenologia da percepção" (p.3). Nesses argumentos, "uma coisa $(\mathrm{X})$ é uma condição necessária para a possibilidade de algo (Y), de modo que (assim se diz) esse último não pode ocorrer sem o primeiro" (ibid.). Para Stern, "ao sugerir que X é uma condição para Y (...), se espera que essa asserção seja metafísica e a priori, e não meramente natural e a posteriori" (ibid.). Quer dizer que os argumentos transcendentais apresentariam "restrições metafisicas" válidas para "cada mundo possível” (ibid.), restrições que Merleau-Ponty também estaria buscando ao se servir de tais argumentos. De modo similar, Taylor (1995) sustenta que "a concepção do sujeito como atividade [agency] encarnada, que se desenvolveu com base na fenomenologia moderna, tal como nos trabalhos de Heidegger e Merleau-Ponty, foi desdobrada e defendida de um modo que por fim é derivado dos argumentos paradigmáticos da primeira Crítica" (p.21-2). Para Taylor, Merleau-Ponty teria mostrado que "nossa percepção do mundo como aquela de um agente encarnado não é um fato contingente que poderíamos descobrir empiricamente" (p.25), mas "uma asserção sobre a natureza de nossa experiência e pensamento" (p.22). Por conseguinte, para ambos os autores, as teses transcendentais não se misturam com constatações factuais.

4 Eis uma lista não exaustiva de interpretações que vão nessa direção: Geraets (1971), Baldwin (2004, p.5-6, 18), Pietersma (2000, p.178), Dillon (1997, xii-xiii), Priest (2003, p.99). Eu vou discutir alguns tópicos dessas interpretações no decorrer do artigo.

5 Acredito que essa consequência está presente na Crítica da razão pura, por exemplo, na seguinte passagem: "a possibilidade de uma experiência em geral e do conhecimento de seus objetos se baseia em três fontes cognitivas subjetivas: sentidos, imaginação, e apercepção; cada um deles pode ser considerado empiricamente, a saber, na aplicação às aparências dadas, mas todos também são elementos ou fundações a priori que tornam o uso empírico possível" (A 115). Também na segunda edição Kant concebe a atividade empírica como fundada por princípios puros: "as sínteses da apreensão, que são empíricas, devem necessariamente estar em acordo com a síntese da apercepção, que é intelectual e contida inteiramente a priori na categoria" (B, 162, nota).

${ }^{6} \mathrm{Na}$ Fenomenologia da percepção, Merleau-Ponty apresenta uma divisão tripartite da obra de Husserl. Há um primeiro período marcado pelo "logicismo" (MERLEAU-PONTY 1997, p.419, nota) das Investigações lógicas, no qual Merleau-Ponty não está muito interessado. O último período se caracteriza por um tipo de "existencialismo" (Id., p.317, nota), e teria antecipado algumas teses defendidas pelo filósofo francês. Entre esses extremos, há o período transcendental idealista - "o período das Ideen” (Id., p.281, nota) - que é severamente criticado por Merleau-Ponty.

7 "Em vez de julgar sobre o ser e não ser da coisa transcendente do momento, consideramos seu conteúdo tal como ele é intuitivamente dado de forma imanente a nós e suposto no fenômeno em questão. Dessa maneira, obtemos intuição evidente da essência do que é transcendente em geral ou de uma coisa transcendente com esse ou aquele aspecto característico" (HUSSERL 1985, \$ 38, p.230).

doispontos, Curitiba, São Carlos, vol. 9, n. 1, p.267-291, abril, 2012 
8 "Nós temos de voltar às fontes originárias de clareza e essencialidade, onde proposição, verdade, falsidade, contradição, e assim todos os conceitos e relações conceituais em questão aqui, estejam diante de nossos olhos, numa doação autêntica, genuína, e nós podemos ver em modos necessários que essa circunstância é fundada na essência dada como um dado e inseparável dela” (HUSSERL 1985, \$ 39, p.235-6).

9 Há muitos textos que analisam as diferenças entre as filosofias transcendentais de Kant e Husserl. Dois artigos sobre esse tema de fácil compreensão e notável pertinência são Nenon (2008) e Luft (2007).

10 Com essa consideração, Merleau-Ponty antecipa uma resposta aos autores que julgaram que ele não foi capaz de desenvolver uma filosofia transcendental plena (Gurwitsch, por exemplo). De fato, esses autores insistem na assunção de um ponto de vista que é desqualificado por Merleau-Ponty. Nesse sentido, não ter se filiado às filosofias transcendentais clássicas não foi uma atestado de incompetência, mas um resultado positivo obtido argumentativamente por Merleau-Ponty.

11 Essa concepção de natureza está presente na Fenomenologia da percepção: "o que é verdadeiro, em suma, é que há natureza, não a das ciências, mas aquela que a percepção me mostra" (MERLEAU-PONTY 1997, p.494).

12 Merleau-Ponty afirma: "o que chamamos de natureza já é consciência da natureza, o que chamamos vida já é consciência da vida e o que chamamos psique ainda é um objeto diante da consciência” (MERLEAU-PONTY 2002, p.199).

13 Após considerar dados da psicologia segundo os quais a linguagem é percebida de modo privilegiado por bebês (em contraste com ruídos aleatórios), Merleau-Ponty conclui: "tão logo a consciência nascente é tomada como objeto de análise, se entende que é impossível aplicar a ela a célebre distinção entre forma a priori e conteúdo empírico" (MERLEAUPONTY 2002, p.185). E, de modo geral, Merleau-Ponty defende que ao menos em um certo nível (antes da projeção dos conhecimentos científicos sobre a experiência), a percepção oferece "estruturas indecomponíveis" (Id., p.186), isto é, conjuntos fenomenais ordenados com um sentido intrínseco, o qual não é derivado de princípios formais exteriores aos próprios dados ali manifestados.

14 Tenho em mente aqui uma passagem famosa de $A$ estrutura do comportamento: "o que há de profundo na noção de Gestalt da qual partimos não é a ideia de significação, mas aquela de estrutura, a junção de uma ideia e de uma existência indiscerníveis, o arranjo contingente por meio do qual os materiais se põem diante de nós para ter um sentido, a inteligibilidade em estado nascente" (MERLEAU-PONTY 2002, p.223).

15 "O criticismo, tendo recalcado cada vez mais a qualidade e a existência, resíduos de sua análise ideal, para coloca-las enfim em uma matéria da qual nada se pode pensar e que portanto é para nós como se não fosse, desdobra de um lado a outro do conhecimento uma atividade homogênea do conhecimento" (MERLEAU-PONTY 2002, p.224).

16 Se essa reconstrução do argumento de Merleau-Ponty está correta, então parece inegável que sua análise da percepção está comprometida com problemas transcendentais (ainda que reformulados). Assim, a abordagem de autores (p. ex., Dreyfus) que selecionam alguns aspec-

doispontos, Curitiba, São Carlos, vol. 9, n. 1, p.267-291, abril, 2012 
tos dessa análise que são mais compatíveis com teorias científicas e minimizam ou nem mesmo mencionam essa perspectiva transcendental parece severamente limitada.

17 Merleau-Ponty afirma em relação à atividade perceptiva: "a percepção existe sempre no modo do 'Se'. Ela não é um ato pessoal pelo qual eu mesmo daria um sentido novo à minha vida. Aquele que, na exploração sensorial, atribui um passado ao presente e o orienta para um futuro não sou eu enquanto sujeito autônomo, sou eu enquanto tenho um corpo e sei 'olhar'” (MERLEAU-PONTY 1997, p.277).

18 Em A estrutura do comportamento, o corpo próprio já é apresentado como constituinte da atividade consciente e não somente como um de seus objetos: "é a cada instante para nós que a consciência experimenta sua inerência a um organismo, pois não se trata de uma inerência a aparelhos materiais, os quais só poderiam ser objetos para a consciência, mas de uma presença à consciência de sua própria história e das etapas dialéticas que ela ultrapassou" (MERLEAUPONTY 2002, p.225).

19 Daí que, rigorosamente falando, não haja uma fenomenologia do corpo próprio na Fenomenologia da percepção, mas sim uma fenomenologia do "sistema corpo próprio-mundo" (MERLEAU-PONTY 1997, p.60).

20 Merleau-Ponty exemplifica esse ponto: "minha atitude nunca é suficiente para me fazer realmente ver o azul ou tocar uma superficie dura” (MERLEAU-PONTY 1997, p. 248).

21 Priest (2003, p.34) e Baldwin (2004, p.18) reconhecem que as capacidades corporais assumem o papel de sujeito transcendental na Fenomenologia da percepção, mas não acentuam a relação circular entre elas e as situações empíricas, justamente uma das principais marcas da nova filosofia transcendental proposta por Merleau-Ponty.

22 Remeto-me aqui à tese de Merleau-Ponty, exposta na primeira seção, de que todo ato reflexivo supõe a vida pré-pessoal da consciência encarnada.

23 Tal como Stern e Taylor sugerem.

\section{Referências bibliográficas}

BALDWIN, T. 2004. "Introduction". In: Baldwin, T. (org.) Merleau-

Ponty. Basic Writings. NY: Routledge, 1-32.

DILLON, M. C. 1997. Merleau-Ponty's Ontology. Evanston:

Northwestern Univ. Press.

DREYFUS, H.; DREYFUS, S. 1999. "The Challenge of MerleauPonty's Phenomenology of Embodiment for Cognitive Science”. In: Weiss, G.; Haber, H. (ed.). Perspectives on Embodiment: The Intersections of Nature and Culture. NY: Routledge, p.103-120. 
DREYFUS, H. 1996. “The Current Relevance of Merleau-Ponty's Phenomenology of Embodiment". The Electronic Journal of Analytic Philosophy, Issue 4, Spring.

GERAETS, T. 1971. Vers une Nouvelle Philosophie Transcendantale - La genèse de la philosophie de M. Merleau-Ponty jusqu'à la Phénoménologie de la Perception. La Haye: Martinus Nijhoff.

GURWITSCH, A. 1957. Théorie du Champ de la Conscience. Paris: Desclée de Brouwer.

HUSSERL, E. 1986. "Die reine Phänomenologie, ihr Forschungsgebiet und ihre Methode - (Freiburger Antrittsrede 1917)". In:Aufsätze und Vorträge 1911-1921. Hua XXV.The Hague: Martinus Nijhoff. 1985. Einleitung in die Logik und Erkenntnistheorie. Vorlesungen 1906/07. Hua. XXIV. Haag: Martinus Nijhoff.

1950. Ideen zu einer reinen Phänomenlogie und phänomenlogischen Philosophie. Erstes Buch. Hua III/1. The Hague: Martinus Nijhoff Publishers, 1950.

KANT, I. 1998. Critique of Pure Reason. Transl. by Guyer, P. and Wood, A.W. Cambridge: Cambridge Univ. Press.

2004. Prolegomena to any Future Metaphysics. Transl. by Hatfield, G. Cambridge: Cambridge Univ. Press.

LUFT, S. 2007. "Desde el ser a lo dado y desde lo dado al ser: algunos comentarios sobre el significado del trascendentalismo ideal en Kant y Husserl” Investigaciones fenomenológicas, n. 5, p.49-83.

MERLEAU-PONTY, M. 2002. La structure du comportment. Paris: PUF, 2002 .

1997. Phénoménologie de la perception. Paris: Gallimard.

NENON, T. 2008. "Some differences between Kant's and Husserl's conceptions of transcendental philosophy". Continental Philosophy Review, Vol. 41, n.4, p.427-439. 
PEREBOOM, D. 1990. "Kant on justification in transcendental philosophy". Synthese 85, p.25-54.

PIETERSMA, H. 2002. Phenomenological Epistemology. Oxford: Oxford Univ. Press.

STERN, R. 1999. "Introduction". In: Stern, R. (ed.) Transcendental Arguments - Problems and Prospects. Oxford: Clarendon Press, p.1-11. 